\title{
mRNA expression profile of selected oxygen sensing genes in the lung during recovery from chronic hypoxia
}

\author{
Alice Panariti, Giuseppe Miserocchi and Ilaria Rivolta* \\ Department of Health Science, University of Milano Bicocca, Via Cadore, 48; 20900 Monza (Italy).
}

\begin{abstract}
This study analyzed the time dependence decay of the mRNA of selected genes important for the hypoxia response. The genes chosen were the two isoforms of hypoxia-inducible factors, the three isoforms of the prolyl hydroxylase domain protein, the vascular endothelial growth factor and endothelial nitric oxide synthase.

mRNA and proteins were extracted from lungs obtained from control, hypoxic and 15 minutes normoxic recovered rats and analyzed by Real-time RT-PCR or by the Western Blot technique.

Results indicated that in normoxia isoform $2 \alpha$ was the more represented hypoxia-inducible factor mRNA, and among the prolyl hydroxylase domain transcripts, isoform 3 was the least abundant. Moreover, in chronic hypoxia only hypoxia-inducible factor $1 \alpha$ and prolyl hydroxylase domain protein 3 increased significantly, while after 15 minutes of recovery all the mRNAs tested were decreased except endothelial nitric oxide synthase mRNA. In terms of proteins, hypoxia-inducible $1 \alpha$ was the isoform more significant in the nucleus, while $2 \alpha$ predominated in the cytosol. While the former was steady even after a brief recovery from hypoxia, the latter underwent a strong degradation.

In conclusion we showed the relevance of the decay in the mRNA and protein levels upon re-oxygenation in normoxia. We believe that this has to be considered in research studies dealing with recovery from hypoxia.
\end{abstract}

Key terms: chronic hypoxia, Hypoxia-inducible Factor, Prolyl Hydroxylase Domain proteins, lung, RT-PCR.

\section{INTRODUCTION}

It is well established that upon hypoxia exposure, the difference in oxygen tension induces the expression of several genes in order to guarantee an adequate response of the living system to the environmental changes and to maintain organ homeostasis as much as possible. In this scenario, the master genes to be considered are the Hypoxia-Inducible Factor (HIF) 1 and 2 (Jiang, 1996) as well as the Prolyl Hydroxylase Domain (PHD) proteins 1, 2 and 3 that, besides their contribution to the regulation of HIFs (Appelhoff, 2004) serve also as oxygen sensors (Fong and Takeda 2008). Several studies have already addressed in depth the kinetics of the onset of the hypoxiadependent response in terms of increase in the level of HIFs, mRNA and protein (Chamboredona, 2011). On the other hand, only few papers were dedicated to the time dependent decay after recovery from hypoxia, a condition that also represents a change in oxygen tension. In in vivo studies, the protein expression level of HIF1 $\alpha$ was halved after 5 minutes of reoxygenation and reached the normoxic level in 60 minutes or even less (Yu, 1998; Stroka, 2001). With regard to mRNA in aquatic organisms such as mantis shrimp and croaker, the level of HIF $1 \alpha$ remains stable for 3 hours of normoxic recovery from hypoxia and declines after 24 hours of normoxic condition (Kodama, 2012; Rahman, 2007).

Chronic hypoxia is common to many disease conditions that share, as a joint feature, an insufficient tissue perfusion. In the lung, prolonged exposure to a low level of oxygen results in a general alteration that culminates in pulmonary arterial hypertension (Rivolta, 2011), a clinical condition that includes a remodeling in the pulmonary vasculature as well as cardiac complications. In this case, in addition to HIFs and PHDs, other two important genes to be considered are those encoding for Endothelial Nitric Oxide Synthase (eNOS, or NOS3) and Vascular Endothelial Growth Factor (VEGF-A, hereinafter VEGF); with their activity, these genes balance the constriction or the dilation of pulmonary vessels and the need for neoangiogenesis.

Due to the clinical relevance of the problem, we believe that a picture of the molecular level of these selected, but crucial, players in the overall lung tissue at the peak of the chronic hypoxia exposure period is missing. Moreover, we also found relevant to investigate the kinetic tissue response in the first minutes of re-oxygenation. If it is proven that the half-life of the proteins involved is in the order of minutes ( $Y u, 1998)$, we think that also mRNA decay should be studied in this time range. In this paper, our challenge is to obtain a "frozen picture", as precise as possible, of the level of few selected mRNAs and proteins in the whole lung at the very end of the chronic hypoxia exposure and after few minutes of normoxia recovery, and to interpret it in the light of the physiological response of the lungs.

\section{METHODS}

Experimental model

Nine male, 5-week-old Wistar rats, weighing 100-125 g (Charler River laboratory, Italy) were randomly assigned to one of the following two groups: a control group (CTRL, $\mathrm{n}=3$ ) and a hypoxic group (HYP, $\mathrm{n}=6)$. The hypoxic group was exposed for one month to normobaric hypoxia $(10 \%$ $\mathrm{O}_{2}$ ) as previously described (Rivolta, 2011). For each group, one rat was housed in each cage with free access to standard rat chow and tap water and a 12 hour light:dark cycle. All 
animal experimentation was performed according to the Care and Use of Laboratory Animals, endorsed by the American Physiological Society.

Tissue sampling

The hypoxic and control rats were sacrificed by cervical dislocation without anesthesia; the chest was opened and the lungs immediately removed. Tissue samples were washed in ice-cold physiological buffer, frozen in liquid nitrogen and stored at $-80{ }^{\circ} \mathrm{C}$ in order to avoid RNA degradation. The entire procedure was completed in 5 minutes from the removal of the animals from the cage, as this was the shortest time compatible with the procedure. For the HYP group, three animals were sacrificed immediately after the end of the hypoxia (also in this case the procedure was completed in 5 minutes, in the text will be indicated as HYP5); three other animals were first allowed to recover for 10 minutes (HYP15) in normoxia.

\section{Total RNA extraction}

$1 \mathrm{ml}$ of Trizol Reagent (Invitrogen) was added to 50-60mg of frozen lung samples and the suspension was homogenized on ice, in order to not damage and to preserve the samples from degradation. Once the tissue was completely homogenized, $0.2 \mathrm{ml}$ of chloroform $/ 1 \mathrm{ml}$ of TRIZOL was added, shaken by hand for ten seconds and maintained on ice for 2 minutes. The samples were centrifuged at $1200 x \mathrm{x}$ for 15 minutes at 4 ${ }^{\circ} \mathrm{C}$ : the aqueous phase that contained RNA was removed and transferred to a new tube with $0.5 \mathrm{ml}$ of isopropanol. After 10 minutes at $4{ }^{\circ} \mathrm{C}$, samples were centrifuged at $12000 \mathrm{xg}$ for 10 minutes at $4{ }^{\circ} \mathrm{C}$. The RNA formed a gel-like pellet on the side and bottom of the tube. The supernatant was removed and the RNA pellet washed with $0.5 \mathrm{ml}$ of $70 \%$ ethanol. After resuspension of the pellet, the tube was centrifuged at 7500xg for 10 minutes at $4{ }^{\circ} \mathrm{C}$, the supernatant removed and the RNA pellet dried in air for 5 minutes. The RNA re-suspended in RNase-free-water (20-50ul, depending on the amount of the RNA pellet) and incubated at $55{ }^{\circ} \mathrm{C}$ for 5 minutes was then stored at $-80^{\circ} \mathrm{C}$. The concentration of RNA in each sample was determined by reading the absorbance of $1 \mu \mathrm{l}$ of each sample with a NANODROP Spectrophotometer (Thermo Fisher). The RNA integrity was assessed by electrophoresis, running $1 \mu \mathrm{g}$ of nucleic acid on agarose gel.

\section{DNase I treatment}

To avoid any DNA contamination, $2 \mu \mathrm{g}$ of RNA were treated with DNase I (Fermentas) according to the manufacturer's protocol. At the end of protocol, samples can be directly used for reverse transcriptase or stored at $-80^{\circ} \mathrm{C}$.

\section{Reverse Transcriptase}

The reverse transcriptase reaction was performed according the protocol of the SuperScript III First-Strand Synthesis SuperMix (Invitrogen) by using $2 \mu \mathrm{g}$ RNA previously treated with DNase I, a reverse transcriptase enzyme (Invitrogen), random hexamers as primers, dNTPs and an RNase inhibitor. The resulting cDNA can be directly used for the Real Time PCR or stored at $-20{ }^{\circ} \mathrm{C}$. Negative controls included samples without RT enzyme and samples in which total RNA was replaced with $\mathrm{ddH}_{2} \mathrm{O}$.
Real Time PCR

Quantitative PCR was performed using the Line-gene $\mathrm{K}$ Real-time PCR Detection System (Bioer) with the use of SYBR Green I Premix Ex Taq (TaKara). Specific primers for rat HIF1 $\alpha$, HIF2 $\alpha$ (o EPAS1), PHD1 (o EGLN2), PHD2 (o EGLN1), PHD3 (o EGLN3), VEGFA, eNOS (or NOS3) and1 85 were designed according to the reported sequences (Table I) using the ProbeFinder Software (Roche). For calculation of threshold cycle $(\mathrm{Ct})$, an efficiency curve was generated using 10-fold dilutions of a randomly chosen cDNA lung sample. These curves were considered acceptable if a difference of $3.3 \pm 0.3$ cycles was demonstrated between each of the 10-fold dilutions and the correlation coefficient of all different sequences was at least 0.99 . Reactions were performed in triplicate, and the negative controls derived from reverse transcription were included in each run. The reaction protocol included an initial step of $20 \mathrm{sec}$ at $95^{\circ} \mathrm{C}$ to activate the polymerase.

Each PCR cycle involved denaturation $\left(95^{\circ} \mathrm{C}, 30 \mathrm{sec}\right)$, annealing $\left(60{ }^{\circ} \mathrm{C}, 30 \mathrm{sec}\right)$ and extension $\left(72{ }^{\circ} \mathrm{C}, 20 \mathrm{sec}\right)$. Fluorescence was measured after each cycle. A melting curve analysis (Amplicon Tm, shown in Table 1), was obtained by increasing the temperature by $0.3^{\circ} \mathrm{C}$ every $10 \mathrm{sec}$, from $60{ }^{\circ} \mathrm{C}$ to $96^{\circ} \mathrm{C}$, and was used to identify a temperature at which only the amplicon and not primer dimers accounted for the SYBR.

Green-bound fluorescence. The relative fold change of expression of the transcripts of target genes was quantified as $2^{-(\Delta C t)}$, where $\Delta \mathrm{Ct}$ was $\mathrm{Ct}$ (target genes) - Ct (housekeeping gene) (Pfaffl , 2006). We selected as housekeeping gene $18 \mathrm{~S}$ rRNA.

\section{Protein extraction}

$40 \mathrm{mg}$ of each sample of lung tissue were homogenized with a glass/glass homogenizer, and nuclear and cytosolic proteins were separately extracted using a commercially available kit (NE-PER Nuclear and Cytoplasmic extraction reagent, Pierce) according to manufacturer's protocol. The protein concentration was assessed using a BCA Protein Assay Kit (Pierce), and Bovine Serum Albumin (BSA) was used for a standard curve. $2 \mu \mathrm{l}$ of each sample were tested to quantify the protein content. Proteins were preserved at $-80{ }^{\circ} \mathrm{C}$ for Western Blot assays.

Western Blots

Cytosolic or nuclear proteins $(30 \mu \mathrm{g})$ of each lung sample fraction were separated by home-made $8 \%$ polyacrylamide gel under reducing conditions and electro-transferred to nitrocellulose paper. To check the success of the transfer, the membranes were incubated on an agitator for 5 minutes with Ponceau Red and then washed three times with deionized water. Blots were blocked for 1 hour in blocking buffer $(5 \%$ skimmed milk powder in TBST) and then incubated overnight at $4{ }^{\circ} \mathrm{C}$ with primary antibody (for HIF1 $\alpha$ and HIF2 $\alpha$ Novus Biologicals, for VEGF Santa Cruz, for Phospho-eNOS Cell Signaling, PHD 1, 2 and 3 Sigma Aldrich). After three washings with TBST, membranes were incubated with secondary antibody (Pierce) for 1 hour at room temperature. The excess of antibody was removed by washing with TBST. aTubulin (Cell Signaling) and Lamin A (Abcam) were used to normalize the cytosolic and nuclear proteins, respectively. Proteins were visualized using ECL detection reagents (Pierce) and an 
TABLE I

PCR primer sequences. Position, melting temperature of the primers (Tm) and of the PCR products (Amplicon Tm), percentage of guanine and cytosine and sequence of both forward and reverse primers of each gene considered in the study

\begin{tabular}{|c|c|c|c|c|c|c|}
\hline Gene & Accession number & Position & $\mathrm{T} \mathbf{m}\left({ }^{\circ} \mathrm{C}\right)$ & $\begin{array}{c}\text { Amplicon } \\
\operatorname{Tm}\left({ }^{\circ} \mathrm{C}\right)\end{array}$ & $\% \mathrm{GC}$ & Sequence \\
\hline \multirow{2}{*}{ HIF1 $\alpha$} & \multirow{2}{*}{ NM_024359.1 } & $1535-1557$ & 60 & \multirow{2}{*}{80,0} & 48 & 5'aagcactagacaaagctcacctg $3^{\prime}$ \\
\hline & & $1590-1609$ & 59 & & 50 & 3'ttgaccatatcgctgtccac5' \\
\hline \multirow{2}{*}{$\mathrm{HIF} 2 \alpha$} & \multirow{2}{*}{ NM_023090.1 } & $35-54$ & 60 & \multirow{2}{*}{85,3} & 55 & 5'ggttaaggaacccaggtgct3' \\
\hline & & $126-145$ & 60 & & 50 & $3^{\prime}$ gcatctcgggatttctcctt5' \\
\hline \multirow{2}{*}{ PHD1 } & \multirow{2}{*}{ NM_001004083.1 } & $1357-1375$ & 60 & \multirow{2}{*}{84,5} & 53 & 5'cggaatccacatgaggtga $3^{\prime}$ \\
\hline & & $1460-1479$ & 59 & & 50 & 3'acctttctgtcccgatgcta5' \\
\hline \multirow{2}{*}{ PHD2 } & \multirow{2}{*}{ NM_178334.3 } & $1018-1037$ & 60 & \multirow{2}{*}{84,2} & 55 & 5'cgagcgagcaagagctaaag3' \\
\hline & & $1140-1159$ & 60 & & 60 & 3'ggcaactgagaggctgtagg5' \\
\hline \multirow{2}{*}{ PHD3 } & \multirow{2}{*}{ NM_019371.1 } & $1069-1088$ & 60 & \multirow{2}{*}{82,8} & 45 & 5'cgtggagcccatttttgata3' \\
\hline & & $1154-1175$ & 59 & & 50 & 3'agtaccagacagtcatggcgta5' \\
\hline \multirow{2}{*}{ VEGF } & \multirow{2}{*}{ NM_001110335.1 } & $518-537$ & 60 & \multirow{2}{*}{80,5} & 35 & 5'aaaaacgaaagcgcaagaaa3' \\
\hline & & $571-590$ & 60 & & 50 & 3'tttctccgctctgaacaagg $5^{\prime}$ \\
\hline \multirow{2}{*}{ eNOS } & \multirow{2}{*}{ NM_021838.2 } & $1107-1126$ & 59 & \multirow{2}{*}{78,8} & 50 & 5'tgaccctcaccgatacaaca3' \\
\hline & & $1148-1166$ & 59 & & 58 & 3'cgggtgtctagatccatgc $5^{\prime}$ \\
\hline \multirow{2}{*}{$\begin{array}{l}\text { 18s } \\
\text { rRNA }\end{array}$} & \multirow{2}{*}{ NC_005113.3 } & $113-135$ & 59 & \multirow{2}{*}{77,5} & 39 & $5^{\prime}$ aatcagttatggttcctttgtcg $3^{\prime}$ \\
\hline & & $152-177$ & 59 & & 38 & 3'gctctagaattaccacagttatccaa5' \\
\hline
\end{tabular}

ImageQuant LAS400 (Ge Healthcare) system. ImageQuant TL software was used for the semi-quantitative analysis of the results, normalizing the values expressed in arbitrary units detected for each protein with respect to the values obtained for $\alpha$-tubulin or lamin A.

Statistical analysis

Statistical analysis of the results obtained from the Real TimePCR analysis of HIF1 $\alpha$ and HIF2 $\alpha$ in control condition was carried out by unpaired two-tailed Student $t$ tests and the significance level was set at $\mathrm{p}<0.01$.

For intergroup comparison (CTRL, HYP5 and HYP15 conditions), the results obtained from Real Time-PCR and Western Blot analysis were tested using one-way ANOVA and the differences were analyzed with post-hoc Bonferroni tests. The significance level was set at $p<0.01$. Data are expressed as the ratio of the hypoxic compared to the normoxic control conditions.

\section{RESULTS}

In this study we relied on a well-known chronic hypoxic animal model (Rivolta, 2011), in which rats exposed to $10 \%$ $\mathrm{O}_{2}$ for four weeks showed a decrease in food and water intake compared to rats maintained in normoxia. This behavior may be related to the reduced homeostatic needs of the animals and to the onset of reduced aerobic metabolic activity (Singh, 1993), seeing that the hypoxic animals moved less than normoxic ones. We previously characterized several functional parameters and in this paper we focused our attention on selected molecular hypoxia targets in the lungs.
Hypoxia response takes place starting from specific characteristics of the tissue in control condition (Heiner, 2010). Here we are interested in studying the response of seven selected genes, HIF1 $\alpha$, HIF2 $\alpha$, PHD1, PHD2, PHD3, VEGF and eNOS, that are expressed in the lung and that are sensitive to chronic hypoxia. In order to provide a profile pattern of mRNA expression of our selected genes, we performed real time PCR on mRNAs that were rapidly extracted from normoxic whole rat lung specimens and immediately frozen in liquid nitrogen. The relative amount of each transcript was calculated as $2^{-\Delta}(\mathrm{Ct})$ using $18 \mathrm{~S}$ rRNA as housekeeping gene. It is now well established that $18 \mathrm{~S}$ rRNA is less sensitive to the effect of hypoxia compared to other housekeeping genes (Nagelkerke, 2010), thus its level of expression is more constant.

In order to compare the target protein level with the mRNA expression found, from the lung of the same animal we obtained the total tissue lysate subdivided into nuclear and cytosolic fractions. We evaluated the protein level of HIFs, VEGF and phospho-eNOS, the functional form of the protein.

As shown in the histogram in Figure $1 \mathrm{~A}$, in normoxic condition HIF $2 \alpha$ mRNA was about 13 -fold more represented in the lung $(29.25 \pm 5.4)$ than HIF1 $\alpha(2.24 \pm 0.38, \mathrm{p}<0.01)$. Interestingly, considering the protein level in the nuclear lysate fraction normalized to lamin A (Fig. 1B), HIF1 $\alpha$ was 5.7-fold more abundant then HIF2 $\alpha$ (1.6 \pm 0.5 vs. $0.28 \pm 0.09$, respectively). The situation was reversed in the cytosol, where a prevalence of HIF $2 \alpha$ on $1 \alpha$ protein (Fig. 1B) was seen. In particular, for HIF $2 \alpha$ the ratio cytosol/nuclear fraction was 17 , revealing a greater amount of the protein in the cytosolic compartment. HIF1 $\alpha$ protein in the cytosol was detected at a very low level with a cytosol/nucleus ratio as low as 0.06 . 
Among the three isoforms of PHD, the mRNA of PHD1 and PHD2 were predominately expressed without significant differences between their levels $(2.37 \pm 0.49$ and $2.84 \pm 0.6$, respectively), while by contrast, isoform 3 was by far the PDH least represented, accounting only for about $6 \%(0.16 \pm 0.055)$ of the total. VEGF, the most significant promoter of angiogenesis, was detected at high level (44.20 \pm 9.4$)$, much more than eNOS, a regulator of vascular tone $(0.6 \pm 0.19)$ (Fig. 1A)

Chronic exposure to low oxygen tension induces a wide range of pathways that are principally orchestrated by the transcription factors HIFs that, due to their very short half-life (Textoris, 2012), are considered as immediate surrogate markers of the status of the cellular oxygenation. If in normoxia HIF protein presents a very fast decline of its expression, it appears to be interesting to evaluate how long hypoxia-sensitive gene transcripts are stable and maintain their level of variation induced by chronic hypoxia stimulus. In order to estimate how the expression profile of our selected genes and their proteins may be affected by a very
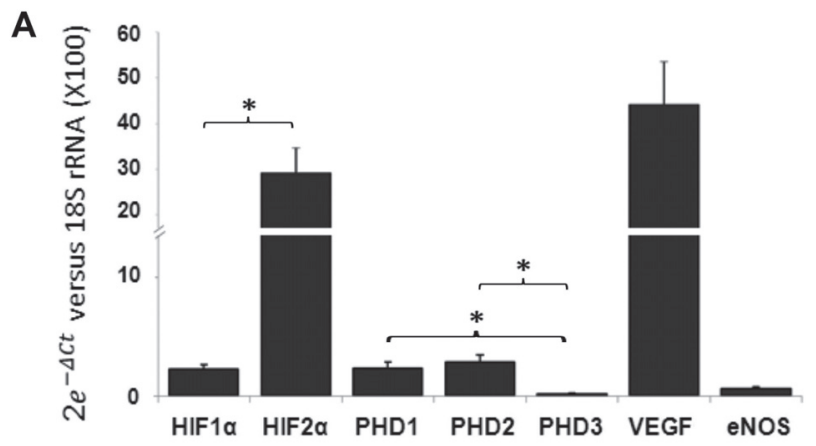

B

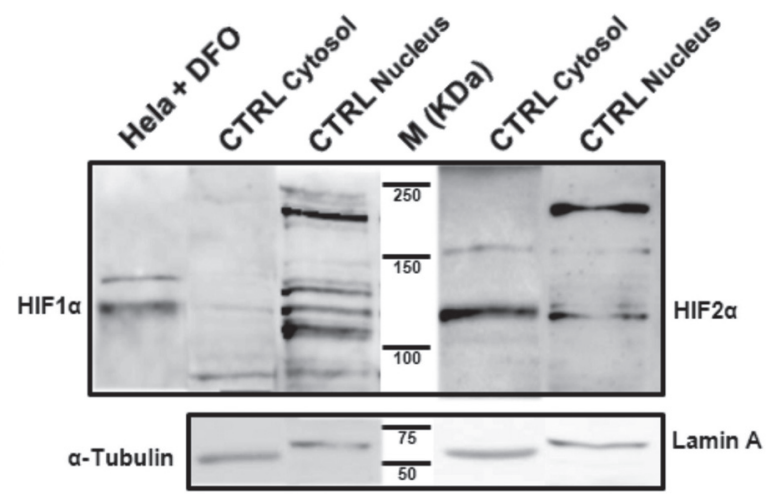

Figure 1. Expression profile of selected transcripts and proteins in the normoxic rat lung. Panel A. The histogram shows on the $y$ axis the relative expression quantified as ${ }^{*} 2^{-\Delta C t}$, of each transcript, where $18 \mathrm{~S}$ rRNA was used as housekeeping gene. In all the experiments $\mathrm{n}=3$ and each sample was tested in triplicate. Data are presented as mean $\pm S D$. The symbol * indicates a significant difference $(p<0.01)$ among the isoforms. Panel B. Representative Western blot analyses of HIF1 $\alpha$ (left) and HIF2 $\alpha$ (right) protein expression in the normoxic lungs. Immunoblots of cytosolic or nuclear extract ( $30 \mu \mathrm{g} / \mathrm{lane}$ ) were probed with HIF $1 \alpha$-specific antibody that identified several bands. As positive control we loaded protein nuclear extract form HeLa cells exposed to desferrioxamine (DFO) $(0.1 \mathrm{mM}$ for 24 hours) which allows discrimination of a specific band at about $120 \mathrm{kDa}$, which we considered as corresponding to HIF $1 \alpha$ protein. For both HIFs, Lamin $A$ and $\alpha$-Tubulin were used as internal standard for nuclear extract and cytosolic extract, respectively. brief recovery to normoxia, we analyzed the level of mRNA and proteins in samples obtained from animals sacrificed immediately at the end of chronic hypoxia period, and from animals sacrificed after 10 minutes in which they were allowed to re-oxygenate in normoxia. More precisely, the lungs of

A

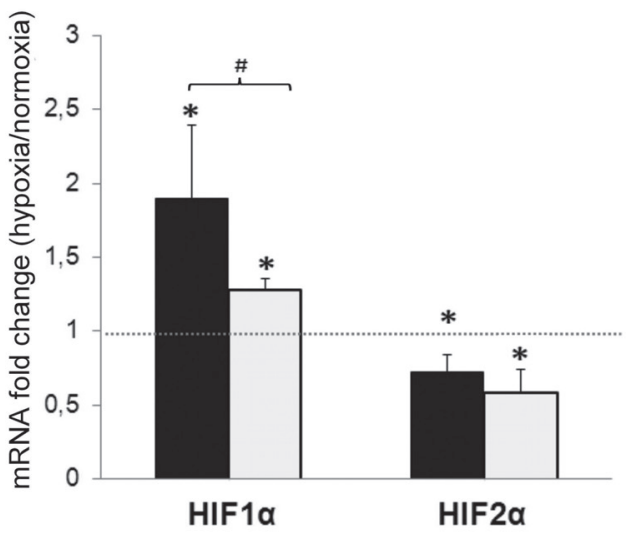

B
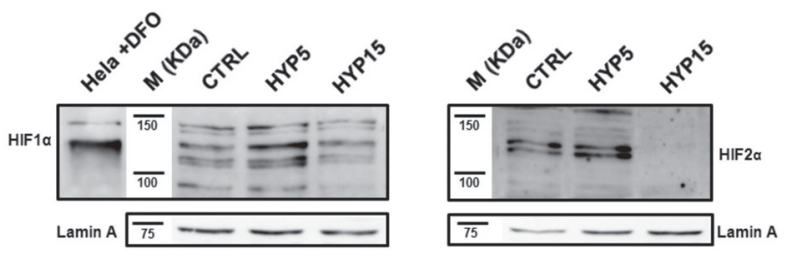

C

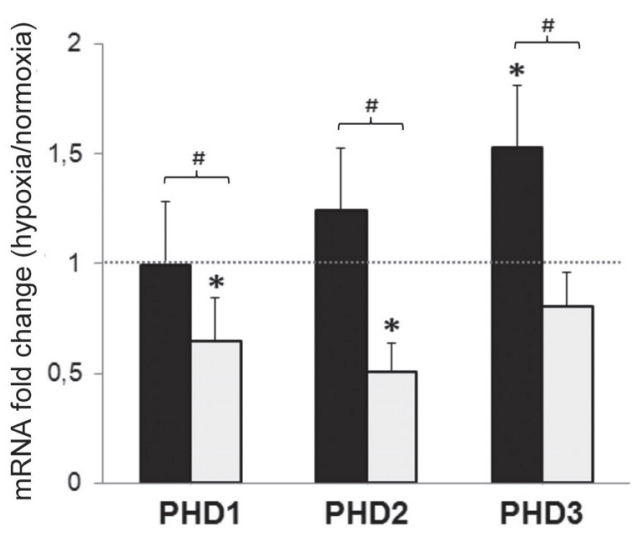

Figure 2. Change in the expression level of selected transcripts and proteins upon hypoxia exposure (HYP5) and after short recovery in normoxia (HYP15). Panel A. The results of quantitative real-time RT-PCR were normalized to the corresponding 18S rRNA and reported as the fold change of hypoxic samples compared to normoxic ones (dashed line). HYP5 (blackbars) represent the averaged data obtained for the specific mRNA in rats immediately sacrificed at the end of the hypoxic period, while HYP15 (graybars) refer to mRNA from samples obtained after 15 minutes of recovery to normoxia. Data are detailed in the text and are presented as mean of $\% \pm$ coefficient of variation. Statistical analysis relative to control and between the groups was set at $\mathrm{p}<0.01$ and indicated in the histograms by the symbols $*$ and \# respectively. Panel B. Representative Western Blot analyses of HIF1 $\alpha$ (left) and HIF2 $\alpha$ (right) protein expression in the nuclear fraction of CTRL, HYP5 and HYP15 lungs. Panel $C$. The bar graph represents the quantitative realtime RT-PCR results obtained for the three isoforms of PHD in HYP5 (black bars) and HYP15 (gray bars) compared to CTRL. Statistical significance relative to the control and between the groups was set at $\mathrm{p}<0.01$ and indicated in the histograms by the symbols * and \# respectively. 
individuals were collected within 5 (HYP5) or 15 minutes (HYP15) from the end of exposure to $10 \% \mathrm{O}_{2}$. Five minutes is the shortest time in which we were able to sacrifice the animal, collect the samples and freeze them in liquid nitrogen.

For each gene, the averaged value representing its expression level was normalized to the averaged value obtained for the same gene in the normoxic CTRL group; in this way, the result is an indication of how many times (fold) hypoxia has modified the expression compared to the normoxic situation. The same approach was used to represent the protein levels. As shown in Figure 2A, hypoxia induced a significant increase of about $90 \%$ of HIF $1 \alpha$ mRNA (1.90 \pm 0.49 fold, $\mathrm{p}<0.01)$ relative to CTRL, which was reduced to only $30 \%$ after re-oxygenation $(1.28 \pm 0.07$-fold relative to CTRL, $\mathrm{p}<0.01)$. HIF $2 \alpha$ mRNA was reduced by approximately $30 \%$ during chronic hypoxia $(0.72 \pm 0.11$-fold relative to CTRL, $\mathrm{p}<0.01)$ and about $20 \%$ further after recovery $(0.58 \pm 0.15$-fold relative to CTRL, p<0.01) (Fig.2A). Comparing with the absolute value, despite this hypoxia-induced decrease the mRNA level of HIF $2 \alpha$ in the lung always remained higher than that of HIF1 $\alpha$.

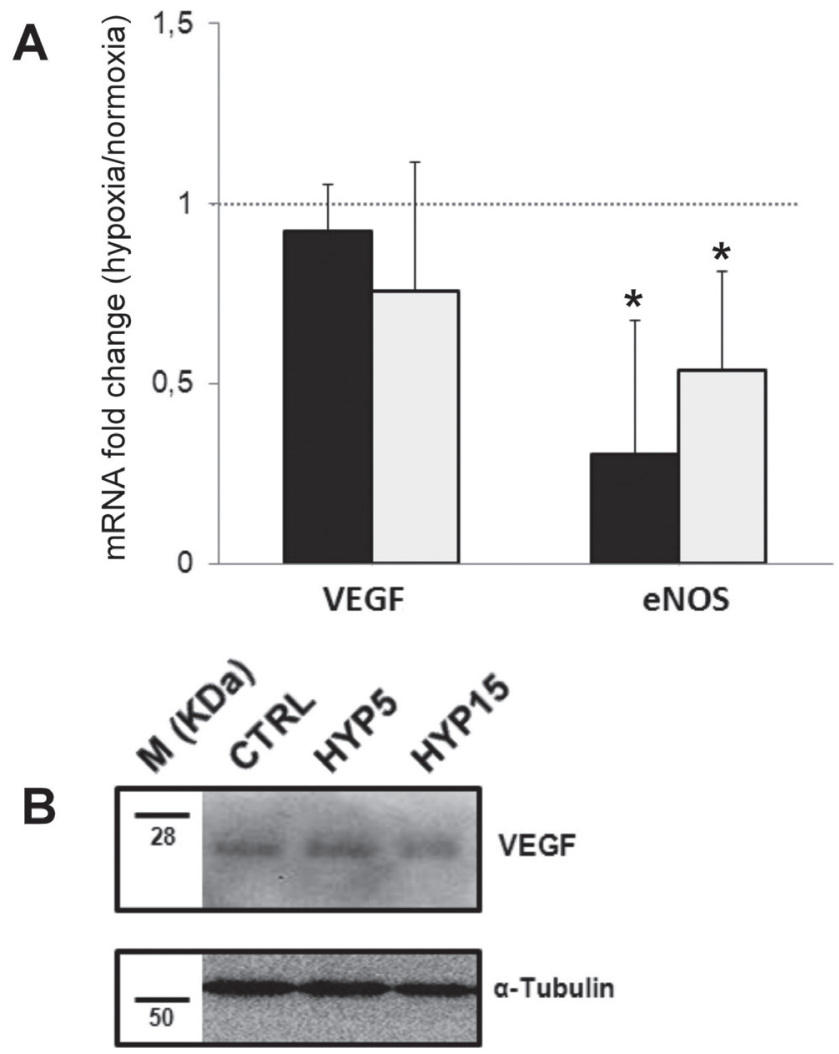

Figure 3. Change in the expression level of VEGF and eNOS transcripts and proteins upon hypoxia exposure (HYP5) and after short recovery in normoxia (HYP15). Panel A represents the results of quantitative real-time RT-PCR normalized to the corresponding $18 \mathrm{~S}$ rRNA and reported as the fold change of hypoxic samples compared to normoxic ones (HYP5, black bars and HYP15, empty bars). Statistical significance relative to the control was set at $\mathrm{p}<0.01$ and indicated in the histograms by the symbol *. Panel $\mathrm{B}$. Representative Western Blot analyses of VEGF protein expression in the cytosolic fraction of CTRL, HYP5 and HYP15 lungs.
Since HIFs exert their functional role in the nucleus, we first considered their protein levels in the nuclear fraction of the tissue lysate (Fig. 2B). HIF1 $\alpha$ remained stable (1.62 \pm 0.5 ; $1.28 \pm 0.5$ and $2.10 \pm 1.4$ in CTRL, HYP5 and HYP15, respectively) as well as HIF2 $\alpha$ in the HYP5 group (1.16-fold), while this last decreased about tenfold in the HYP15 samples compared to the CTRL baseline $(0.28 \pm 0.09,0.24 \pm 0.19$ and $0.03 \pm 0.02$ in CTRL, HYP5 and HYP15, respectively). In the cytosolic tissue fraction, the latter protein remained fairly constant (data not shown).

With respect to PHDs (Fig. 2C) after lowering $\mathrm{O}_{2}$, only PHD3 significantly increased its expression (1.5 \pm 0.28 -fold relative to CTRL, $\mathrm{p}<0.01$ ), while the other isoforms remained unchanged compared to their normoxia levels. Fifteen minutes of re-oxygenation induced a significant reduction of the PHD1 and PHD2 transcripts: about 35\% (0.65 \pm 0.19 -fold relative to CTRL, $\mathrm{p}<0.01)$ and $50 \%(0.50 \pm 0.13$-fold relative to CTRL, $\mathrm{p}<0.01$ ), respectively, as well as of PHD3, which returned to the basal condition.

Figure 3A shows that the relative expression of VEGF was steady after chronic hypoxia, and slightly decreased by about $20 \%$ during recovery ( $0.80 \pm 0.36$-fold relative to CTRL). By contrast, eNOS was significantly reduced overall with a greater difference found for the samples processed within 5 minutes. In HYP5 the transcript reached $30 \%$ of the basal level $(0.30 \pm 0$ 37-fold relative to CTRL, $\mathrm{p}<0.01$ ) while in HYP15 it doubled $(0.58 \pm 0.27$-fold relative to CTRL, $\mathrm{p}<0.01)$. The protein level of these last two targets was evaluated only in the cytosolic fraction of the tissue lysate, since this is their functional location. While for VEGF we detected a steady level of the protein $(0.05 \pm 0.01 ; 0.07 \pm 0.02$ and $0.06 \pm 0.01$ in CTRL, HYP5 and HYP15, respectively) (Fig. 3B), we were not able to detect any phospho-eNOS, which is the functional form of the protein, probably due to its low level of expression (data not shown).

\section{DISCUSSION}

The turnover of mRNA is extremely important for the homeostasis of cells, and in general for organisms, because it allows the fine regulation of a wide variety of transcripts relevant for physiological functions. Moreover, it enables the tissues to tune rapidly the response to changes in extrinsic stimuli, such as those present in the local environment.

The time course of the up-regulation of genes in hypoxia is widely studied, but few data are available for the in vivo time dependence decay of the mRNA level during recovery to normoxia. We believe that this kinetics is of interest, especially if we consider not only people returning from high altitude expeditions, but also people recovering from disease conditions (reperfusion after ischemia or improvement from pulmonary hypertension).

We learned at our expense (struggling in the recent past to have reproducible data) that in this kind of study many different technical parameters need a tight control, and moreover that the delay between the end of the hypoxic period and the sacrifice of the animal is crucial, even if it is a matter of a minute. Moreover, after the sacrifice there is another factor that must be considered: the mRNA of both target and housekeeping genes in a dead body degrades during the post-mortem interval. Based on the literature (Zhao, 2006), we calculated that within the first hour after death one can extrapolate $10 \%$ degradation of the total lung mRNA, thus we 
considered the limit of five minutes necessary for us to process the samples to be a safe interval to work with.

The mRNA of inducible genes such as the hypoxiasensitive ones is known to be less stable in-vitro than that of constitutively expressed genes. Moreover, in the rates of mRNA degradation (decay) of different human cell lines (Yang, $2003)$, a small percentage $(\sim 5 \%)$ of expressed transcripts was found to have "fast" decay rates (half-life $<2 \mathrm{~h}$ ) and among these were the transcription-related transcripts. This may be the case for HIFs, and in the second instance, of the HIFdependent transcripts. Therefore, it might be expected that, since these genes present a rapid increase in transcription upon hypoxia exposure, they may have a fast decay in their level as well with the return to normoxic condition. For this reason, the goal of our work was to produce a frozen picture of the potentials of the lung tissue in hypoxia as well as after a very brief recovery in normoxia. We believe that the mRNA analysis may be very representative of this aim. In fact, transcription is the closest step to the sensing of a change; moreover, any variation in the mRNA level may, in the very near future, be decoded into a variation in protein translation and ultimately in tissue function. Of course we also evaluated the protein level, but as the results show, when looking for whole tissue responses to an environmental change this approach was less sensitive and more subject to inter-individual heterogeneity, as the high degree of variation suggests. This high variability may also be explained by the consideration that lungs as a whole are composed of many different cell types (the principal being endothelial, epithelial, macrophages and smooth muscle cells), and for each of them proteins have mechanisms of stabilization or degradation that may be very specific. (Burke, 2002; Talks, 2000; Galbán, 2009, Bárdos, 2005; Feldser, 2009; Agani, 2000).

For clarity we now discuss the targets studied separately.

\section{HIFs and PHDs}

Our data collected from CTRL samples showed that in the rat lung HIF $2 \alpha$ mRNA is much more expressed ( 14 fold) than HIF1 $\alpha$. At the protein level we found that in the nucleus, where HIFs exert their functional role, HIF1 $\alpha$ was predominant compared to HIF $2 \alpha$, but still this latter is highly represented in the cytosolic fraction of the lung lysate, much more than the $1 \alpha$ isoform. This is in line with the literature, where it is reported that while HIF1 $\alpha$ is ubiquitously expressed, HIF2 $\alpha$ has more limited tissue distribution with prevalence in tissues regulating oxygen delivery such as endothelial cells and lung type II pneumocytes (Wiesener, 2003). Moreover, lung normal tissue (non-tumor) macrophages and hypoxic lung macrophages accumulate HIF2 $\alpha$ rather than HIF1 $\alpha$, and its expression is higher in the cytoplasm than in the nucleus (Burke, 2002; Talks, 2000). Indeed, lungs are enriched in both these types of cells. Overall our data also suggest that in normoxia HIF $2 \alpha$ is the most relevant isoform of HIF, important for the regulation of the lung homeostasis.

Comparing the mRNA levels of the HIF and PHD mRNAs, our results are also in line with those of Appelhoff (Appelhoff, 2004), indicating that probably PHD3 is important for the regulation of HIF $2 \alpha$ in the whole lung tissue, since a low level of mRNA of the regulator protein is paralleled by the high level of the mRNA of the transcription factor.

Upon chronic hypoxia exposure we found that HIF1 $\alpha$ mRNA, but not HIF2 $\alpha$, was indeed overexpressed in the samples obtained from group HYP5, becoming in relative terms the predominant isoform responsible for tissue response and the more sensitive to the $\mathrm{O}_{2}$ reduction. Of course, since our interest is related to the lung tissue, we cannot exclude tissue specificity in the response (Wiesener, 2003). Nevertheless, this result may be explained by the stabilization of HIF1 $\alpha$ mRNA in hypoxia (Lang, 2002; Görlach, 2000). When the hypoxic stimulus disappears, HIF1 $\alpha$ mRNA is no longer stabilized, which supports our results showing that in fifteen minutes of recovery to normoxia the tissue lost about $67 \%$ of HIF $1 \alpha$ mRNA expression, which, as a trend, represents a very fast kinetics of decay. In fact, assuming a linear degradation rate from our data, the half-life of HIF $1 \alpha$ mRNA is 22 minutes. Similar results were already reported in a monolayer cell culture study, where the half-life of HIF1 $\alpha$ mRNA was 10 minutes (Prabhakar and Semenza, 2012). In fact, if we consider a simple system we could speculate that following a decrease on $\mathrm{O}_{2}$ tension, a high level of HIF1 $\alpha$ mRNA produces a high level of HIF1 $\alpha$ protein that may remain steady and exert its function because it is not counterbalanced by a sufficiently high level of PHD2, since its mRNA level remained low in hypoxia. Unfortunately, the system is not that simple, as well reviewed by Galbán and Gorospe (Galbán, 2009). For HIF1 $\alpha$, the protein expression level is the result of complex regulation at transcriptional, post-transcriptional, translational and post-translational levels. Nowadays, we know that a number of additional regulatory mechanisms appear to operate to determine the final protein concentration, some of which fall outside the canonical degradation pathway, such as protein-protein interaction, trophic stimuli and reactive oxygen species (Bárdos, 2005; Feldser, 2009; Agani, 2000). A possible role for hypoxia-induced microRNAs may be one of the reasons why we did not detect an increase of the HIF1 $\alpha$ at the protein level (Bruning, 2011; Kelly, 2011; Chan, 2010). A second reason may be related again to the complex composition of the lung tissue with several cell types that may have different HIF regulation. In A549 epithelial cells an acute hypoxia exposure produces an increase in HIF1 $\alpha$ protein level, but prolonged exposure to low oxygen tension failed to demonstrate HIF1 $\alpha$ protein accumulation, probably due to a negative feedback regulation that decreased its mRNA stability. In contrast, HIF2 $\alpha$ protein stimulation remained stable also upon prolonged hypoxia, probably due to transcriptional activation rather than to a change in mRNA stability. In smooth muscle cells, another constituent of the lung tissue, in prolonged hypoxia endothelin-1 induces HIF1 $\alpha$ synthesis and reduces PHD2-dependent down-regulation (Pisarcik, 2013) and angiotensin II and thrombin increase HIF1 $\alpha$ stability, as mediators of the regulation at transcriptional and translational levels (Page', 2008).

In general terms, we note that all the HIF and PHD mRNAs considered in this paper presented a very rapid decay upon re-oxygenation. This represents a novelty that may deserve to be investigated in detail by more appropriate studies. We believe that pathways responsible for mRNA degradation and / or impairment of transcript stability could explain our new finding.

\section{VEGF}

One of the most important adaptations in chronic hypoxia is angiogenesis, a process that involves the growth of new blood vessels from preexisting ones, in order to provide blood supply 
and subsequent oxygen and nutrient delivery to deficient tissues. In these conditions, angiogenesis is mainly determined by HIF-dependent transcription of VEGF (Shweiki, 1992). It has already been demonstrated that in-vitro the mRNA level of VEGF increased up to 12 fold, and besides being more transcribed, it is also stabilized post-transcriptionally (Levy, 1995). Thus, it might be surprising that in our results we did not find a hypoxia-dependent increase in VEGF mRNA, despite the fact that it has been reported that prolonged exposure to hypoxia eventually down-regulates transcriptional activation of VEGF (Kuo, 1999; Olfert, 2001). Again, we may argue that we are working with the lung as a whole organ. In our previous paper (Rivolta, 2011), we observed a remarkable heterogeneity in the lung response to hypoxia in terms of perfusion control, allowing blood flow distribution to lung regions that still retained diffusion properties, thus adapted to hypoxia, and reducing it in the areas where the typical features of a good diffuser are lost. Thus we believe that the results we obtained here represent an average of the whole tissue condition, and this is also reflected in the high coefficient of variation. Our group is currently working to verify this hypothesis by analyzing the expression level of VEGF in different regions of the lung exposed to chronic hypoxia. In terms of VEGF protein, we did not detect any significant difference among the normoxic and hypoxic rats.

eNOS

The expression level of eNOS is crucial for the production of nitric oxide in endothelial cells. Our results confirm previous data in which after chronic hypoxia the decrease in eNOS mRNA was explained by a down-regulation at transcriptional and post-transcriptional levels (McQuillan, 1994; Ho, 2012) with a shortening of the eNOS mRNA half-life. Not all studies are in agreement, but one should notice that our data show almost a doubling in the level of eNOS mRNA after only 15 minutes of recovery in normoxia. We thus hypothesize that in these experiments timing plays a crucial role. The reason why eNOS is down-regulated in hypoxia may be explained, again, by the presence of areas of the lung where perfusion is highly reduced. The reduction of blood flow by itself reduces eNOS mRNA (Le Cras, 1998), and less blood means also low oxygen tension, in a combination of microenvironmental conditions that leads in a single direction a decrease in eNOS expression. Probably, the degree of the reduction parallels the degree of extension of the region of the lungs that does not diffuse any more. Again this is an interesting point to address in the near future.

\section{CONCLUSION}

We presented in this paper the possibility to detect in a whole lung tissue sample the mRNA of HIF1 $\alpha, \operatorname{HIF} 2 \alpha$, the three isoforms of PHD, VEGF and eNOS. We show for the first time that in normoxia, despite the prevalence of HIF $2 \alpha$ mRNA, in the nuclear extract the HIF1 $\alpha$ protein is predominant, while in the cytosolic fraction it is hardly detectable and HIF $2 \alpha$ is highly present. Among the three PHD isoforms the PHD3 mRNA is the most abundant, while eNOS mRNA transcripts appear to be very few. In hypoxia, instead, it is the HIF1 $\alpha$ which is up-regulated, even though this is hard to discriminate at the protein level, while the HIF $2 \alpha$ protein presents a very rapid decay upon re-oxygenation. We did not find hypoxiadependent significant differences in the mRNA and protein level for VEGF, while eNOS messenger was decreased in hypoxia and the normoxic stimulus up-regulated it. We believe that the biological relevance of this paper relies in part in the consideration that when dealing with the whole organ instead of monolayer cells, the response to certain stimuli may be somewhat different since the organ is the ensemble of different cell types that may react differently to the same challenge. Moreover, the recovery from hypoxia exhibits a very rapid kinetics of decay, both for mRNAs and for proteins responding to $\mathrm{O}_{2}$ concentration. We take our results as an opportunity to suggest to other researchers to be very careful in analyzing the time-dependence of recovery from hypoxia.

\section{ACKNOWLEDGEMENTS}

This work was funded by an institutional grant (Fondo di Ateneo per la Ricerca, Università Milano-Bicocca). The authors thank the fellows of the laboratory of Prof. DiFrancesco D. (University of Milano) for technical help and hospitality and the laboratory of Strazzabosco M. (University of Milano Bicocca) for assistance.

\section{REFERENCES}

AGANI FH, PICHIULE P, CHAVEZ JC, LAMANNA JC (2000). The role of mitochondria in the regulation of hypoxia-inducible factor 1 expression during hypoxia. J Biol Chem. 275:35863-35867.

APPELHOFF RJ, TIAN YM, RAVAL RR, TURLEY H, HARRIS AL, PUGH CW, RATCLIFFE PJ, GLEADLE JM (2004) Differential function of the prolyl hydroxylases PHD1, PHD2, and PHD3 in the regulation of hypoxia-inducible factor. J Biol Chem. 279:38458-38465.

BÁRDOS JI, ASHCROFT M (2005). Negative and positive regulation of HIF1: a complex network. Biochim Biophys Acta. 1755:107-20.

BRUNING U, CERONE L, NEUFELD Z, FITZPATRIC SF, CHEONG A, SCHOLZ CC, SIMPSON DA, LEONARD MO, TAMBUWALA MM, CUMMINS EP, and TAYLOR CT (2011). MicroRNA-155 Promotes Resolution of Hypoxia-Inducible Factor $1 \alpha$ Activity during Prolonged Hypoxia. Mol Cell Biol. 31: 4087-4096.

BURKE B, TANG N, CORKE KP, TAZZYMAN D, AMERI K, WELLS M, LEWIS CE (2002). Expression of HIF-1alpha by human macrophages: implications for the use of macrophages in hypoxia-regulated cancer gene therapy. J Pathol.196:204-212.

CHAMBOREDONA S, CIAISA D, DESROCHES-CASTANA A, SAVID P, BONOD F, FEIGEA JJ, CHERRADIA N (2011) Hypoxia-inducible factor- $1 \alpha$ mRNA: a new target for destabilization by tristetraprolin in endothelial cells. Molecular Biology of the Cell.22:3366-3378.

CHAN SY and LOSCALZO J (2010). MicroRNA-210. A unique and pleiotropic hypoxamir. Cell Cycle 9:1072-1083.

FELDSER D, AGANI F, IYER NV, PAK B, FERREIRA G, and SEMENZA GL (1999). Reciprocal Positive Regulation of Hypoxia-inducible Factor 1a and Insulin-like Growth Factor 2. Cancer Res. 59:3915-3918.

FONG G-H AND TAKEDA K. (2008) Role and regulation of prolyl hydroxylase domain Proteins. Cell Death and Differentiation 15:635-641.

GALBÁN S and GOROSPE M. (2009) Factors interacting with HIF-1 $\alpha$ mRNA: novel therapeutic targets. Curr Pharm Des. 15:3853-3860.

GÖRLACH A, CAMENISCH G, KVIETIKOVA I, VOGT L, WENGER RH, GASSMANN M (2000) Efficient translation of mouse hypoxia-inducible factor-1alpha under normoxic and hypoxic conditions. Biochim Biophys Acta. 1493:125-134

HEINER M, SRIRAM K (2010) Structural Analysis to Determine the Core of Hypoxia Response Network. PLoS ONE 5(1): e8600. doi:10.1371/journal. pone.0008600.

HO JJ, MAN HS, MARSDEN PA (2012) Nitric oxide signaling in hypoxia. J Mol Med (Berl). 90:217-231.

JIANG B-H, SEMENZA GL, BAUER C, MARTI HH (1996) Hypoxia-inducible factor 1 levels vary exponentially over a physiologically relevant range of $\mathrm{O} 2$ tension. Am. J. Physiol. C1172-C1180. 
KELlY TJ, SOUZA AL, CLISH CB, and PUIGSERVER P (2011). A HypoxiaInduced Positive Feedback Loop Promotes Hypoxia-Inducible Factor 1 Stability through miR-210 Suppression of Glycerol-3-Phosphate Dehydrogenase 1-Like. Mol and Cell Biol. 31:2696-2706.

KODAMA K, RAHMAN MS, HORIGUCHI T, THOMAS P (2012) Assessment of hypoxia-inducible factor- $1 \alpha$ mRNA expression in mantis shrimp as a biomarker of environmental hypoxia exposure. Biol Lett. 8:278-281.

KUO NT, BENHAYON D, PRZYBYLSKI RJ, MARTIN R, LAMANNA JC (1999) Prolonged hypoxia increases vascular endothelial growth factor mRNA and protein in adult mouse brain. J. Appl. Physiol. 86:260-264.

LANG KJ, KAPPEL A, GOODALL GJ (2002) Hypoxia-inducible Factor-1 mRNA Contains an Internal Ribosome Entry Site That Allows Efficient Translation during Normoxia and Hypoxia. Mol. Biol. Cell. 13:1792-1801.

LE CRAS TD, TYLER RC, HORAN MP, MORRIS KG, TUDER RM, MCMURTRY IF, JOHNS RA, ABMAN SH (1998) Effects of chronic hypoxia and altered hemodynamics on endothelial nitric oxide synthase expression in the adult rat lung. J Clin Invest. 101:795-801.

LEVY AP, LEVY NS, WEGNER S, GOLBERG MA (1995) Transcriptional regulation of rat vascular endothelial growth factor gene by hypoxia. J. Biol. Chem. 270:13333-13340.

MCQUILLAN LP, LEUNG GK, MARSDEN PA, KOSTYK SK, KOUREMBANAS S (1994) Hypoxia inhibits expression of eNOS via transcriptional and posttranscriptional mechanisms. Am. J. Physiol. 267:H1921-H1927.

NAGELKERKE A, MUJCIC H, WOUTERS B, SPAN PN (2010) $18 \mathrm{~S}$ is an appropriate housekeeping gene for in vitro hypoxia experiments. British J. of Cancer 103, 590.

PRABHAKAR NR, SEMENZA GL (2012) Adaptive and maladaptive cardiorespiratory responses to continuous and intermittent hypoxia mediated by hypoxia-inducible factors 1 and 2. Physiol. Rev. 92:9671003.

HUANG LE, ARANY Z, LIVINGSTON DM, BUNN HF (1996) Activation of hypoxia-inducible transcription factor depends primarily upon redoxsensitive stabilization of its alpha subunit. J. Biol. Chem. 271:3225332259.

OLFERT M, BREEN EC, MATHIEU-COSTELLO O, WAGNER PD (2001) Chronic hypoxia attenuates resting and exercise-induced VEGF, flt-1, and flk-1 mRNA levels in skeletal muscle. J. Appl. Physiol 90:1532-1538.

PAGE’ EL, CHAN DA, GIACCIA AJ, LEVINE M, and RICHARD DE (2008) Hypoxia-inducible Factor-1 Stabilization in Nonhypoxic Conditions: Role of Oxidation and Intracellular Ascorbate Depletion. Mol. Biol. of the Cell 19:86-94.

PFAFFL MW (2006) Relative quantification. In DORAK MT (ed) Real-time PCR (Advanced Methods). International University. pp 63-82.

PISARCIK S, MAYLOR J, LU W, YUN X, UNDEM C, SYLVESTER JT, SEMENZA GL, SHIMODA LA (2013). Activation of Hypoxia-Inducible
Factor-1 in Pulmonary Arterial Smooth Muscle Cells by Endothelin-1. Am J Physiol Lung Cell Mol Physiol. [Epub ahead of print].

RAHMAN, MS, THOMAS P (2007) Molecular cloning, characterization and expression of two hypoxia-inducible factor alpha subunits, HIF1a and HIF-2a, in a hypoxiatolerant marine teleost, Atlantic croaker (Micropogonias undulatus). Gene 396: 273-282.

RIVOLTA I, LUCCHINI V, ROCCHETTI M, KOLAR F, PALAZZO F, ZAZA A, MISEROCCHI G (2011) Interstitial pressure and lung oedema in chronic hypoxia. Eur. Respir. J. 37:943-9.

SINGH SB, SELVAMURTHY, W (1993) Effect of intermittent chronic exposure to hypoxia on feeding behaviour of rats. Int J Biometeorol. 37:200-2.

SHWEIKI D, ITIN A, SOFFER D, KESHET E (1992) Vascular endothelial growth factor induced by hypoxia may mediate hypoxia-initiated angiogenesis. Nature. 359:843-845.

STROKA DM, BURKHARDT T, DESBAILLETS I, WENGER RH, NEIL DA, BAUER C, GASSMANN M, CANDINAS D (2001) HIF-1 is expressed in normoxic tissue and displays an organ-specific regulation under systemic hypoxia. FASEB J. 15:2445-2453.

TALKS KL, TURLEY H, GATTER KC, MAXWELL PH, PUGH CW, RATCLIFFE PJ, and HARRIS AL (2000). The Expression and Distribution of the Hypoxia- Inducible Factors HIF-1a and HIF-2a in Normal Human Tissues, Cancers, and Tumor-Associated Macrophages. Am. J of Pathology, 157:411-421.

TEXTORIS J, BEAUFILS N, QUINTANA G, LASSOUD AB, ZIELESKIEWICZ L, WIRAMUS S, BLASCO V, LESAVRE N, MARTIN C, GABERT I, LEONE M (2012) Hypoxia-inducible factor (HIF1 $\alpha$ ) gene expression in human shock states. Crit Care. 16:R120.

WIESENER MS, JÜRGENSEN JS, ROSENBERGER C, SCHOLZE CK, HÖRSTRUP JH, WARNECKE C, MANDRIOTA S, BECHMANN I FREI UA, PUGH CW, RATCLIFFE PJ, BACHMANN S, MAXWELL PH, ECKARDT KU (2003) Widespread hypoxia-inducible expression of HIF-2alpha in distinct cell populations of different organs. FASEB J 17:271-273.

YANG E, VAN NIMWEGEN E, ZAVOLAN M, RAJEWSKY N, SCHROEDER M, MAGNASCO M, DARNELL JE JR (2003) Decay rates of human mRNAs: correlation with functional characteristics and sequence attributes. Genome Res 13:1863-1872.

YU AY, FRID MG, SHIMODA LA, WIENER CM, STENMARK K, SEMENZA GL (1998) Temporal, spatial, and oxygen-regulated expression of hypoxia-inducible factor-1 in the lung. Am. J. Physiol 275:L818-L826.

ZHAO D, ZHU BL, ISHIKAWA T, QUAN L, LI DR, MAEDA H (2006) Realtime RT-PCR quantitative assays and postmortem degradation profiles of erythropoietin, vascular endothelial growth factor and hypoxiainducible factor 1 alpha mRNA transcripts in forensic autopsy materials. Leg. Med. 8:132-136. 